\title{
O LETRAMENTO CIENTÍFICO COMO PRÁTICA NO ITINERÁRIO FORMATIVO DE UM BOLSISTA DE INICIAÇÃO À DOCÊNCIA
}

\author{
The Scientific Literacy as Practice in the Formative Itinerary of a Scholarship Holder of \\ a Teaching Initiation Program
}

\author{
Nestor Barbosa de Oliveira-Junior ${ }^{1}$ \\ David Santana Lopes ${ }^{2}$
}

\begin{abstract}
Resumo: Orientando-se pelos princípios do Letramento Científico, o presente estudo irá narrar os enlaces formativos de um professor em formação, participante do Programa Institucional de Bolsas de Iniciação à Docência (PIBID), a partir de intervenções didáticas desenvolvidas em uma escola pública da cidade Salvador (Bahia) entre julho de 2018 e agosto de 2019. Essas experiências conduzirão a escrita deste estudo, apresentando como método de análise os princípios das Narrativas Autobiográficas obtidas em cada intervenção didática realizada, além das conquistas e obstáculos que despontaram durante essa trajetória debutante como professor-pesquisador. As etapas essenciais que compõem o método são: a) descrição do contexto acerca do itinerário formativo; b) realização de um balanço de aprendizagens; c) definição da narrativa; d) interpretação sobre as experiências vivenciadas e; e) complementos de significação. As narrativas discutem sobre os desafios e reflexões ao incorporar em sua prática docente perspectivas para um Ensino de Ciências que se opõe a modelos mecânicos e transmissivos. Os pressupostos teóricos do Letramento Científico possibilitaram ao exbolsista, durante seu itinerário formativo, uma visão expandida da função social da atividade científica. Tais experiências podem contribuir para discussões acerca do perfil de professores que se pretende construir nos cursos de Licenciatura e nos programas de Formação Inicial.
\end{abstract}

Palavras-chave: Letramento Científico. PIBID. Itinerários Formativos.

Abstract: Guided by the principles of Scientific Literacy, the present study will narrate the training links of a teacher in training, participating in the Institutional Program for Teaching Initiation Scholarships (PIBID), from didactic interventions developed in a public school in the city of Salvador (Bahia) between July 2018 and August 2019. These experiences will guide the writing of this study, presenting as a method of analysis the principles of the Autobiographical Narratives obtained in each didactic intervention performed, in addition to the achievements and obstacles that emerged during this debutant trajectory as a teacher researcher. The essential steps that make up the method follow: a) description of the context about the formative itinerary; b) carrying out a learning balance; c) definition of the narrative; d) interpretation of the experiences and; e) meaning complements. The narratives discuss the challenges and reflections when incorporating perspectives for a Sciences Teaching that is opposed to mechanical and transmissive models in their teaching practice. The theoretical

\footnotetext{
1 Graduando em Licenciatura em Ciências Biológicas pela Universidade Federal da Bahia (UFBA).Orcid: https://orcid.org/0000-0001-8943-8858. E-mail: nestor_barbosa12@hotmail.com

${ }^{2}$ Mestre em Educação e Licenciado em Ciências Biológicas pela Universidade Federal da Bahia (UFBA). Pedagogo pela Universidade Salvador (UNIFACS) e Especialista em Letras/Libras pela Universidade do Estado da Bahia (UNEB). Orcid: https://orcid.org/0000-0002-0217-2709. E-mail: acdc.santana@gmail.com
} 
assumptions of Scientific Literacy enabled the ex-scholarship holder, during his formative itinerary, an expanded view of the social function of scientific activity. Such experiences can contribute to discussions about the profile of teachers that are intended to be built in the Undergraduate courses and in the Initial Training programs.

Keywords: Scientific Literacy. PIBID. Formative itineraries.

\section{Introdução}

A formação de professores no Brasil tem sido objeto de investigação constante e revelam resultados diversificados tanto sobre os seus problemas, como os avanços ao longo da história. Junto a essa trajetória formativa da classe docente no país, Saviani $(2013$, p. 1) afirma que detalhar "uma visão de conjunto da história da educação brasileira [é uma forma de] auxiliar os professores no trabalho pedagógico que realizam com seus alunos nas salas de aulas". Sendo assim, compreender a própria edificação do sistema de ensino no Brasil é uma parte integrante para o reconhecimento dos itinerários formativos contemporâneos.

Nesse sentido, o ponto inicial de discussão sobre a trajetória docente neste estudo é a partir da criação das chamadas Escolas Normais, consideradas na literatura (SAVIANI, 2009) como o primeiro movimento nacional na formação de professores no país. Em síntese, de acordo com Borges (2011), durante o desenvolvimento do movimento, as Escolas Normais foram transformadas em um processo formativo pautado em métodos transmissivos, se distanciando das discussões didáticas e pedagógicas, antes tomadas como orientadoras para a edificação do professorado.

As tentativas de incorporação de discussões mais amplas ao processo de formação de professores acerca de questões pedagógicas em detrimento de uma formação técnica, tomaram forma apenas com as reformas das instituições públicas no Estado de São Paulo em 1890. Nesse sentido, despontam os chamados reformadores (SAVIANI, 2009), professores amparados em processos pedagógicos de vanguarda e alinhados com o objetivo de articulação das demandas sociais da época com o desenvolvimento de uma melhor prática docente.

As ideias reformistas culminam em 1924 na Associação Brasileira de Educação (ABE) e na formulação do Instituto de Educação, que além de endossarem as ideias modernas na formação de professores, tornam-se ambientes para a pesquisa em educação (BORGES, 2011). Surgia a necessidade no Brasil da qualificação profissional de professores para além da formação implementada nas escolas secundaristas. Se constituem neste ponto, as Universidades, que aliadas com as propostas das escolas novistas, propõe espaços importantes de produção e divulgação das ciências (GADOTTI, 1999).

Imerso nessa premissa, o crescimento de movimentos liberais tecnicistas em todo o mundo reverberou também na formação de profissionais das mais diversas áreas no Brasil, priorizando a formação técnica para atender as demandas do mercado (FREITAS, 2002). Historicamente, a presença do pensamento de formação tecnicista permeou diversos momentos na trajetória formativa de professores, com destaque ao período da ditadura militar e ao período de redemocratização do Brasil no fim dos anos 1980.

A partir do início dos anos 2000, já com a existência das Leis de Diretrizes e Bases da Educação Brasileira (BRASIL, 1996) e com a promulgação das Diretrizes Curriculares Nacionais para a Formação de Professores (DCN), novos avanços nos currículos possibilitaram a retomada de uma discussão mais profunda sobre uma abordagem formativa centrada no desenvolvimento de competências pessoais, sociais e profissionais dos professores (BORGES, 2011). Em suma, as DCN são consideradas como um dos maiores 
avanços curriculares no país, inserindo orientações mais assertivas para a presença da prática pedagógica, agora presente desde o início do percurso formativo dos estudantes de Licenciatura. Esse movimento deu origem a reformas nas estruturas pedagógicas dentro de Instituições de Ensino Superior (IES), solidificando o espaço para a construção de programas de formação inicial de professores, como o Programa Institucional de Bolsas de Iniciação à Docência (PIBID).

Criado em 2007, o PIBID é inicialmente desenvolvido para atender uma demanda de licenciados da área das Ciências Exatas e Naturais, ampliando-se dois anos depois para os demais campos do saber e de seus respectivos cursos de licenciatura, e é compreendido como uma política governamental que vem constituindo um importante avanço para a formação inicial de professores (SILVA, 2017). O programa é fruto de um processo de reformulação perante a histórica deficiência na formação de licenciados, buscando constituir um espaço de articulação entre a Educação Básica e a Universidade. A estrutura de gerência do PIBID em cada IES é composta por uma Coordenação Geral, Coordenação de Subprojetos, Professores/as Supervisores/as provenientes de escolas públicas e estudantes de licenciatura.

Cada Universidade é responsável pela elaboração do regimento interno do PIBID, adicionando novos objetivos, que também subsidiam os subprojetos desenvolvidos por cada curso de Licenciatura. Com base nessa premissa, que o presente trabalho busca apresentar os itinerários formativos de um ex-bolsista de Iniciação à Docência do subprojeto Biologia da Universidade Federal da Bahia (UFBA).

A experiência narrada neste estudo ocorreu em mais um ciclo de trabalhos do subprojeto de Biologia/UFBA, entre julho de 2018 e agosto de 2019. A escolha desse programa governamental para subsidiar as experiências a serem descritas, parte da afirmação de Lira-da-Silva (2014, p. 58) ao destacar o PIBID da Licenciatura em Ciências Biológicas como uma construção essencialmente colaborativa com professores universitários e da Educação Básica, tendo como objetivo principal "contribuir para a formação de licenciados em Biologia, instrumentalizando-os para o exercício da docência, valorizando-a como uma atividade intelectual, crítica e reflexiva".Pesquisas sobre o PIBID de Biologia/UFBA indicam que as atividades desenvolvidas vêm possibilitando a consolidação da formação profissional docente dos estudantes (LIRA-DA-SILVA, 2014; LIRA-DA-SILVA et al., 2018; LOPES et al., 2018).

Em resumo, a atuação dos bolsistas nas escolas ocorreu através do desenvolvimento de intervenções didáticas. Tais ações são caracterizadas como projetos desenvolvidos diretamente pelos estudantes bolsistas, com orientação/supervisão da coordenação do subprojeto e das professoras do ambiente escolar. O tema e método que fomentaram essas intervenções eram determinadas por livre escolha dos estudantes. Madeira e Bomfim (2020) destacam ainda que:

Partindo destas concepções de autonomia, embasadas em liberdade responsável, desejo, tomada de decisão e autorregulação da aprendizagem, o subprojeto PIBID Biologia/UFBA aposta na possibilidade do licenciando escolher as atividades de iniciação à docência que irá desenvolver em seu processo de tornar-se professor (MADEIRA; BOMFIM, 2020, p. 2).

A livre escolha da temática tem como consequência uma vasta gama de diferentes possibilidades pedagógicas para a discussão no escopo das Ciências Biológicas, além de abordagens teóricas e práticas das mais diversas ordens, perfil do PIBID Biologia/UFBA, assim como mostra o trabalho de Lira-da-Silva (2014). No ciclo de atividades iniciadas no ano de 2018, buscou-se explorar tais ações ao incentivar os bolsistas a elaborarem seus 
próprios eixos de atividades, na qual os mesmos poderiam optar por desenvolvê-las dentro dos objetivos sugeridos. O eixo CineBiologia que, inclusive, orientou as intervenções didáticas que serão apresentadas mais adiante nesta pesquisa, pautava-se na produção de mídias amadoras que abordem as questões sociocientíficas, além do estímulo no desenvolvimento de debates entre os estudantes e mediadores em relação a temáticas contemporâneas que envolvam a Biologia (MADEIRA; BOMFIM, 2018) frente às produções cinematográficas.

Madeira e Bomfim (2020, p.2) ressaltam que os momentos formativos assumem uma noção de formação que "favoreça ao licenciando desenvolver suas próprias concepções e etnométodos para sua futura atuação profissional, a partir da sua interação com outros sujeitos sociais e com o contexto do ambiente escolar". Desta forma, a escolha de pressupostos filosóficos por conta própria, potencializa o processo de autonomia do estudante no desenvolvimento de suas práticas de pesquisa. Nesse contexto e orientando-se pelos princípios do Letramento Científico (LC), o presente estudo irá narrar os enlaces formativos de um professor em formação a partir de intervenções didáticas desenvolvidas em uma escola pública da cidade Salvador (Bahia) entre julho de 2018 e agosto de 2019. Essas experiências conduzirão a escrita deste estudo, apresentando como método de análise os princípios das Narrativas Autobiográficas (NÓVOA; FINGER, 2010) obtidas em cada intervenção, além das conquistas e obstáculos que despontaram na trajetória debutante como professor-pesquisador.

\section{Enlaces Entre o Ensino de Ciências e de Biologia com o Letramento Científico}

O contexto do Ensino de Ciências no Brasil é marcado por um processo de repetição de fórmulas, definições e classificações (KRASILCHIK, 2008; DEL PINO; STRACK, 2012), e mesmo com debates cada vez mais presentes na formação inicial e continuada de professores, práticas mecânicas e rotineiras ainda são muito presentes nas salas de aula (PINHÃO; MARTINS, 2016). Ausubel (2012) defende que a construção de uma estrutura geral que favoreça a aprendizagem significativa no Ensino de Ciências é fundamental, através do conhecimento historicamente acumulado do aprendiz, com valorização as suas singularidades, e formação de uma concepção da Ciência que seja articulada com as relações de Ciência, Tecnologia, Sociedade e Ambiente (CTSA).

Krasilchik e Marandino (2004) já discutiam que o Ensino de Ciências deveria ser caracterizado como um processo que possibilite ao cidadão oportunidades de participação ativa em suas próprias experiências formativas, assim como das responsabilidades e dos desafios presentes no cotidiano de ensino. Para Souza e Alves (2017), o crescimento ao acesso à informação em especial àquelas relacionadas com áreas científicas e tecnológicas, reverberam no cotidiano escolar, fazendo com que o professor não mais deva abordar os conteúdos de ciência de forma reprodutivista, mas sim, focada na construção do conhecimento que promova a reflexão sobre esses conhecimentos.

O termo Letramento Científico (LC) tem origem na língua inglesa como scientific literacy, e tem como proposta inicial o desenvolvimento de habilidades do fazer científico, através de um currículo escolar atento ao cotidiano e ao desenvolvimento da ciência (SASSERON; CARVALHO, 2011). Historicamente, a definição de Letramento Científico como a do Programa Internacional de Avaliação de Alunos (PISA), vem balizando a construção de documentos orientadores para a educação no Brasil. Mais recentemente, a Base Nacional Comum Curricular (BNCC) assume o compromisso direto no desenvolvimento do Letramento Científico para a área das Ciências da Natureza, envolvendo a "capacidade de compreender e interpretar o mundo (natural, social e tecnológico), mas também transformá-lo com base nos aportes teóricos e processuais da ciência” (BRASIL, 2017, p.273). 
Del Pino e Strack (2012) destacam que o LC tem como objetivo não só desenvolver capacidades estudantis voltadas apenas para nomear ou conceituar objetos de ensino, mas analisar e interpretar informações sob diferentes modalidades, perspectivas e especificidades. As práticas pautadas nos pressupostos teóricos do Letramento Científico alinhadas as discussões do BNCC, devem fomentar um espaço propício ao desenvolvimento de habilidades tais como a leitura e a formulação de hipóteses, a reflexão crítica de fatos cotidianos na tomada de decisões ancoradas nos saberes científicos (BRANCO et al., 2020).

Mesmo sendo princípios amplamente discutidos na literatura e classificados como essenciais na maior parte das abordagens voltadas para a educação científica, a implementação das ações específicas do Letramento Científico ainda é, por vezes, simplificada ou adotada erroneamente, principalmente na área das Ciências da Natureza. Acerca desse contexto, Mamede e Zimmermann (2005, p. 2) afirmavam há mais de 15 anos que os estudos na área das Ciências da Natureza "tem-se utilizado indiscriminadamente [...] do letramento científico [ignorando a] importância de preparar o indivíduo para a vida em uma sociedade científica e tecnológica, na qual o conhecimento assume um papel essencial, dentro de uma perspectiva crítica da ciência e da tecnologia".

Imerso nesse contexto, o Ensino de Biologia apresenta características particulares e desafiadoras para alunos e professores. A presença de terminologias e conceitos com representações distantes da realidade do estudante representam desafios (SOUZA; RESENDE, 2016). Se somados a mecanismos didáticos que valorizam a memorização em detrimento da reflexão e da postura crítica, faz com que os estudantes passem a não relacionar o que aprendem na vida cotidiana, sem desenvolvimento da capacidade de emprego dos conceitos em distintos contextos (ALBUQUERQUE; BRAGA; GOMES, 2012).

Em complemento, Souza e Strohschoen (2016, p. 9), ratificam que ações implementadas em torno de práticas concretas voltadas ao LC podem contribuir não só "significativamente na melhoria e no poder de argumentação dos alunos ao expressar suas ideias [mas também] a inserção da leitura e da escrita nas aulas de Biologia como condicionante essencial para o aprofundamento dos argumentos sobre [...] os desafios inerentes à Biologia". Para isso, o desenvolvimento de práticas e intervenções precisa se manter alicerçado em um planejamento pedagógico articulado que contemple exatamente as demandas do espaço de ensino em questão.

Nesse cenário, estão as intervenções didáticas desenvolvidas pelos autores do presente estudo que buscaram se opor às práticas tradicionais do Ensino de Ciências através de abordagens metodológicas que integrem os pressupostos teóricos do Letramento Científico (DEL PINO; STRACK, 2012) com atividades que fomentam espaços de reflexão sobre a ciência e a sua relação com a própria comunidade escolar no qual foram realizadas as atividades. Para isso, as intervenções didáticas desenvolvidas foram ancoradas em práticas cujo desenvolvimento possibilitasse alcançar os objetivos para a construção de um indivíduo que possa gradualmente, durante as correlações com outros campos do conhecimento, obter competências e saberes cientificamente letrados.

\section{Percurso metodológico}

Esta produção acadêmica de cunho qualitativo (FLICK, 2009, p. 203) pautou a construção em torno da "elaboração de uma [...] sequência histórica da vida, de estruturas processuais que dominam a experiência e que estão presentes nos momentos individuais da vida". Têm-se a valorização de um estudo não apenas sobre dados qualitativos, mas experiências capazes de elaborar uma produção que seja relevante dentro do contexto no qual 
ela se insere, nesse caso, a formação docente. Desta forma, este texto seguiu tais princípios para elencar as narrativas advindas dos itinerários formativos de um licenciando, que se fazem presentes na interação com os sujeitos nos diferentes espaços da pesquisa.

Partindo da chamada "abstração analítica" (FLICK, 2009), o presente estudo relata as experiências vivenciadas por um ex-bolsista de iniciação à docência a partir de duas intervenções didáticas denominadas de "Luz, Vida, Ação: Criando roteiros cinematográficos sobre a Biologia" e "A Evolução pela Alimentação", realizadas nas instalações do Colégio Estadual Ministro Aliomar Baleeiro (CEMAB) na cidade de Salvador (Bahia). Durante o estudo participaram vinte e cinco estudantes como sujeitos da pesquisa, todos cursando, na ocasião, o $3^{\circ}$ ano do Ensino Médio do CEMAB. As atividades contaram ainda com o preenchimento do Termo de Consentimento Livre e Esclarecido (TCLE) pelos estudantes, além do Termo de Anuência Institucional assinado pela Coordenação Pedagógica.

Essas atividades se apoiaram em práticas Educomunicativas (SOARES, 2011) e nos pressupostos teóricos do Letramento Científico. Ambas as intervenções culminaram em um projeto de pesquisa maior intitulado "Como estudantes de uma escola pública de Salvador compreendem termos científicos ligados a Biologia”, temática na qual os presentes autores se debruçam até hoje a partir de distintas produções científicas. Em síntese, foram adotados como instrumentos de pesquisa para a análise documental questionários semiestruturados, roteiros de observação e questionário de avaliação final. Como recurso didático, utilizamos o documentário produzido pela Discovery Channel, "A Evolução pela Alimentação", cujo conteúdo atrelava o processo de evolução dos seres humanos ao hábito de alimentação, abordando assim diversos conceitos biológicos.

A utilização de Recursos Audiovisuais (RA) tal como séries, filmes e documentários, têm se consolidado como importante ferramenta para a melhoria dos processos de ensino e aprendizagem (LEITE; RIBEIRO, 2012). No contexto do Ensino de Biologia, estudos vêm indicando que a utilização de RA possibilitou a construção de um ambiente educacional que favoreceu não só a compreensão de conceitos científicos, mas também a reflexão sobre os conteúdos abordados (GONÇALVES; MACIEL; BARROS, 2017; SOUSA, 2020).

O documentário foi dividido em três partes, apresentadas durante três etapas diferentes, no qual foram preenchidos roteiros de observação pelo pesquisador e um questionário semiestruturado pelos estudantes. As questões presentes nos questionários foram elaboradas a partir dos conceitos científicos ligados à biologia presentes no documentário, apresentadas tanto nas questões objetivas, quanto nas questões discursivas.

Como mencionado, esse estudo analisou experiências obtidas em cada um desses momentos de catarse com base no método (Auto)Biográfico de Nóvoa e Finger (2010, p. 24) no qual afirmam que quando a literatura trata da "formação de formadores", "dificilmente poderemos pretender interferir na formação dos outros, sem antes termos procurado compreender o nosso próprio processo de formação". Contudo, mesmo em meio a dados sensíveis e intrassubjetivos como em estudo acerca de itinerários formativos, os autores estabelecem algumas métricas capazes de organizar as informações experienciadas. A autora Adéle Chené (2010), pesquisadora convidada para integrar a escrita da obra supracitada de Nóvoa e Finger (2010), descreve cinco etapas essenciais para compor o método (Auto)Biográfico. Dentre essas etapas estão:

a) descrição do contexto acerca do itinerário formativo. No presente estudo, essa descrição é sobre os estudantes e espaços de ensino de cada uma das intervenções pedagógicas analisadas pelos autores desta produção acadêmica; 
b) realização de um balanço de aprendizagens; c) definição da narrativa e d) interpretação sobre as experiências vivenciadas. Neste momento essas três etapas ocorrem simultaneamente durante o método (Auto)Biográfico já que elas dialogam em torno dos enlaces do próprio autor com os demais sujeitos e objetos que o circundam.

e) Complementos de significação é o momento destinado a expandir as interpretações individuais e coletivas atribuídas nas etapas anteriores, permitindo, de acordo com Chené (2010, p. 128), que "os formandos devem retomar por si próprios os discursos interpretativos que os levam a compreender o sentido da sua experiência de formação". Essa etapa é contemplada através do tópico "Produções e reflexões sobre o itinerário formativo", no qual essa catarse é implementada pelos autores da obra.

Por fim, Chené (2010) aponta ainda que tal método (Auto)Biográfico, mesmo detalhado de forma coerente em cada etapa descrita acima, se faz necessário a imersão em uma abordagem ou aporte teórico orientador que intercruze todas as informações produzidas. Neste caso, as diferentes dimensões que compõem o Letramento Científico (DEL PINO; STRACK, 2012) serão os eixos orientadores do diálogo acerca das narrativas apresentadas.

\section{Construindo narrativas através de intervenções didáticas}

A Educomunicação, campo que une as áreas da educação e comunicação, nasce em meio às ditaduras latino-americanas dos anos 1960, como movimento de resistência ao autoritarismo (CITELLI; SOARES; LOPES, 2019). Segundo Soares (2011), o movimento educomunicativo é uma ação emergente entre dois campos tradicionais, pressupondo ambientes educativos dialógicos, colaborativos, críticos e criativos, em que a comunicação seja entendida como um direito humano e, assim, possibilite a expressão dos seus sujeitos.

Em complemento, Jaques e Copelli (2014) enxergam na prática educomunicativa uma possibilidade concreta de educar a sociedade para a evolução, participação cidadã e democracia, pautadas nos direitos humanos. No contexto de ensino formal, a Educomunicação propõe o intercâmbio de conhecimento, empoderando os educandos sobre o seu processo de aprendizagem e de autorreconhecimento (ITOCAZO, 2017). Experiências como as de Sebastião, Bortoliero e Lira-da-Silva (2013) discutem que a Educomunicação trouxe contribuições significativas para a construção do conhecimento científico e na formação do pensamento crítico com jovens dentro dos espaços educativos trabalhados.

Para Moreira (2017), a utilização dos pressupostos educomunicativos fomentam a interconexão dos debates entre a ciência com outras áreas do saber, do trabalho em equipe e da formação do professor enquanto mediador. Desta forma, no contexto escolar, a Educomunicação abre-se como uma possibilidade de refletir os saberes, como sendo um modo de pensar e agir essencialmente crítico (SOARES, 2011).

Nesse contexto, pautado nos pressupostos do Letramento Científico, da Educomunicação e nas experiências de Sebastião et al. (2013), a primeira intervenção pedagógica "Luz, Vida, Ação: Criando roteiros cinematográficos sobre a Biologia" foi implementada. Em suma, essa intervenção buscou elaborar roteiros cinematográficos que abordassem conteúdos de Biologia, como ferramentas didáticas para promoção de uma postura crítica dos estudantes através do uso de práticas comunicativas.

Inserida nesta intervenção, foi realizada com os estudantes a "Oficina de Roteiros Cinematográficos", que envolveu as seguinte etapas: 1) Oficina de Produção de Roteiros, momento em que os estudantes foram apresentados a técnicas de elaboração desse instrumento; 2) Pré-Alimentação, etapa voltada para a escuta e debate entre os estudantes sobre os conteúdos e definiçãa de temas; 3) Construção de Roteiros e Reuniões de Orientação, 
Revista de Educação, Ciência e Tecnologia

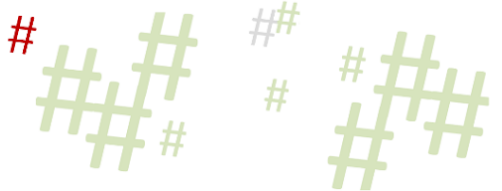

pensando para a prática, onde estudantes construíram suas estratégias de pesquisa e sistematizaram os materiais coletados e 4) Apresentação das Atividades, a culminância da oficina no qual os estudantes puderam compartilhar o resultado do seu trabalho.

Os estudantes utilizaram como ponto de partida os assuntos abordados na $3^{\text {a }}$ unidade do ano letivo e definiram como temática geral a abordagem dos sistemas do corpo humano, construindo roteiros alicerçados em discussões de diferentes esferas sociais, como a saúde, meio ambiente, tecnologia e cidadania. Cinco roteiros foram produzidos por cada estudante participante com os seguintes temas: Sistema Digestivo, Sistema Reprodutor, Sistema Linfático, Sistema Nervoso e Sistema Respiratório (Figura 1).

Figura 1 - Página inicial dos roteiros cinematográficos desenvolvidos pelos estudantes. A) Sistema Digestivo; B) Sistema Reprodutor; C) Sistema Linfático; D) Sistema Nervoso e E) Sistema Respiratório.
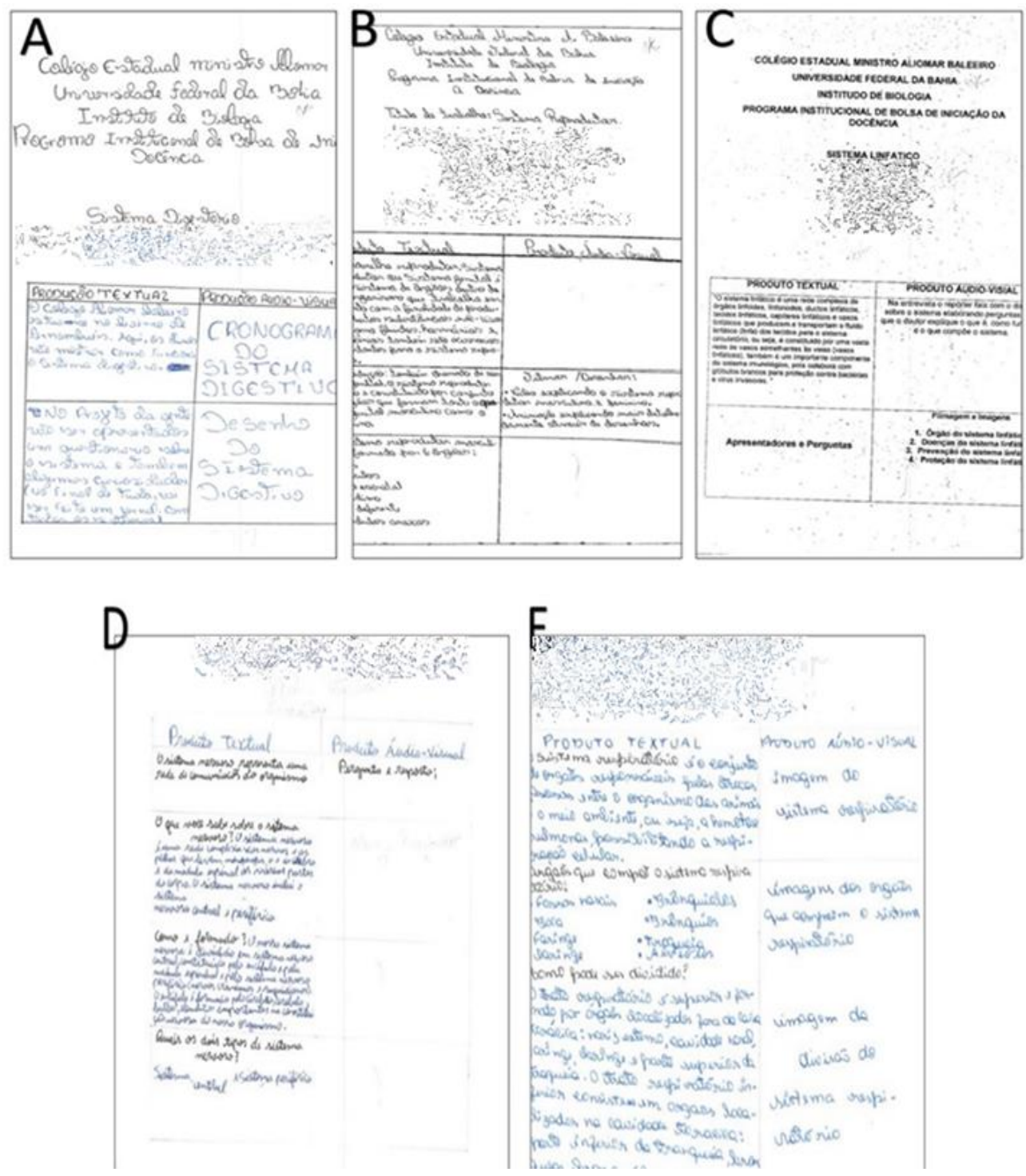

Fonte: Elaborado pelos autores (2018).

Durante as etapas de construção e orientação, momento de expansão do diálogo entre os participantes, foi notório como estudantes, aos poucos, foram incrementando em seus discursos elementos cada vez mais distantes do senso comum. A cada rodada de discussão, os 
discentes aprofundavam suas reflexões, a exemplo da construção do roteiro sobre o sistema respiratório, no qual os estudantes conseguiram em diversos momentos romper a descrição funcional do sistema e discutir sobre preservação ambiental, manutenção de áreas verdes, efeitos da industrialização, poluição atmosférica e os efeitos negativos na saúde, tal como as neoplasias. A Tabela 1 mostra os conteúdos abordados pelos estudantes e as dimensões de letramento científico identificadas nos roteiros produzidos.

Tabela 1 -Roteiros produzidos por estudantes do CEMAB e análise das dimensões de Letramento Científico

\begin{tabular}{c|l}
\hline \multicolumn{1}{c|}{ Conteúdo } & \multicolumn{1}{|c}{ Dimensões de Letramento Científico Observadas } \\
\hline Sistema Digestivo & $\begin{array}{l}\text { Ao discutir sobre as funções do sistema digestivo, os estudantes abordaram a } \\
\text { necessidade de uma alimentação saudável, relatando sucintamente os } \\
\text { malefícios do consumo de alimentos processados. }\end{array}$ \\
Sistema Reprodutor & $\begin{array}{l}\text { A abordagem do sistema reprodutor foi pautada na discussão sobre doenças } \\
\text { sexualmente transmissíveis e na importância do uso de métodos de } \\
\text { contraceptivos. } \\
\text { Os estudantes apresentaram dificuldades na construção do roteiro, mas ainda } \\
\text { assim discutiram questões como a importância no cadastro das pessoas como } \\
\text { doadoras de medula óssea. }\end{array}$ \\
Sistema Linfático & $\begin{array}{l}\text { Os estudantes foram capazes de discutir sobre o consumo de álcool e seu } \\
\text { impacto sobre as funções motoras, assim como discutir o perigo do consumo } \\
\text { de drogas seguido de atividades que requerem atenção, como dirigir. }\end{array}$ \\
Sistema Nervoso & $\begin{array}{l}\text { Os estudantes foram capazes de discutir questões como preservação ambiental, } \\
\text { manutenção de áreas verdes urbanas, efeitos da industrialização sobre a } \\
\text { qualidade do ar e prejuízos do uso de cigarros. }\end{array}$ \\
\hline
\end{tabular}

Fonte: Elaborado pelos autores (2021).

Ainda que a escrita dos roteiros produzidos em alguns casos não conseguisse representar todas as reflexões presentes nas discussões, o processo metodológico de construção dos roteiros, embasados nos pressupostos Educomunicativos e do Letramento Científico, apresentaram-se como ferramentas capazes de promover o diálogo entre os conteúdos abordados no Ensino de Biologia e reflexões de relevância humanística e social. Para os estudantes, a realização da atividade trouxe desafios, principalmente por estarem imersos em um contexto educacional marcado pela repetição e memorização de conteúdo.

Ao fim das atividades, os estudantes relataram a dificuldade em compreender a intervenção desenvolvida como parte do programa de aulas, já que o conteúdo foi abordado fora do método expositivo, segundo eles, aproximando-se mais de uma dinâmica do que uma "aula de verdade". Porém, foi consenso entre os discentes, que atividades nesse modelo (mais dialógico e menos expositivo) atraem mais interesse. Sebastião et al. (2013) afirmam em seu estudo, que a prática educomunicativa é capaz de aumentar o engajamento dos estudantes na abordagem de temas científicos, como foi o caso da intervenção.

No que se refere às experiências do ex-bolsista, pode-se afirmar que também houve desafios. Os pressupostos presentes nos referenciais teóricos orientaram a elaboração dos elementos didáticos e da práxis pedagógica para um caminho diferente do comum. Desta forma, abdicar da aula expositiva é difícil, pois essa representa muitas vezes, um local confortável para o professor. A utilização das práticas educomunicativas e do LC exigem a ruptura da zona de conforto, pois deslocam o professor do centro do processo educativo e o coloca no mesmo horizonte de seus educandos. 
Como já explicitado, durante o processo de discussão da atividade para produção de roteiros sobre os sistemas humanos, foi possível perceber que os estudantes conseguiram fundamentar reflexões e conceitos envolvidos, porém, no momento da escrita, erros conceituais estavam presentes em todos os roteiros produzidos. Com base nessas informações, foi possível perceber que os estudantes apresentaram dificuldades para desenvolver argumentações embasadas no conhecimento científico, utilizando comumente elementos do senso comum para justificar suas respostas. A Figura 2 sistematiza as quatro dimensões necessárias para o estabelecimento de conexões para o LC definidos pelo PISA: contextos, competências, atitudes e conhecimentos.

Figura 3 - As inter-relações do PISA para as dimensões de Letramento Científico

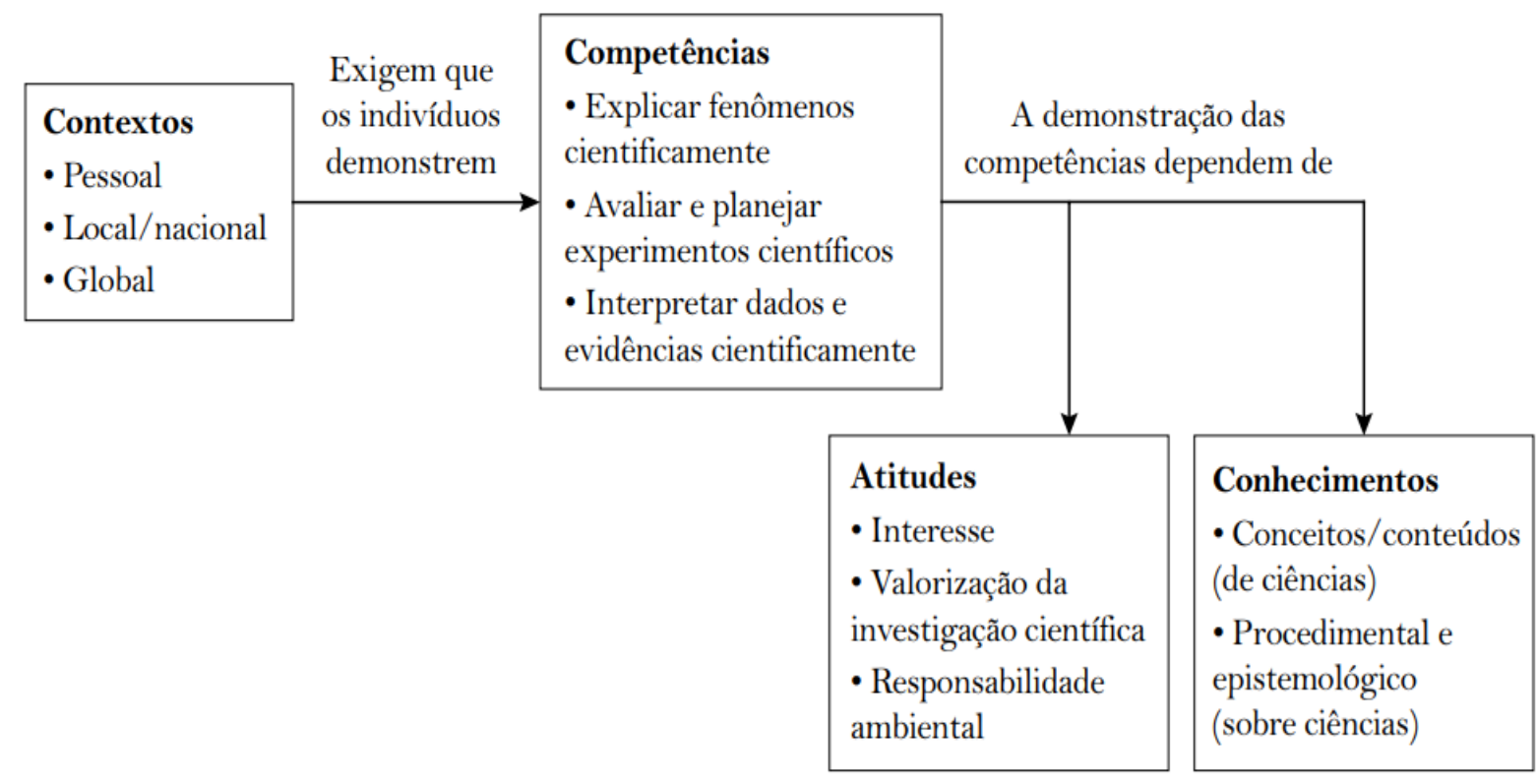

Fonte: Branco et al. (2020).

As recentes avaliações do PISA, ainda que pautadas por uma racionalidade técnica, expõem exatamente as dificuldades que os estudantes brasileiros têm na avaliação de seus conhecimentos em torno de conteúdos de ciência e seus reflexos socioculturais. Os resultados, quando analisados sob a luz de tais inter-relações, indicaram ainda que os estudantes apresentaram dificuldades principalmente na dimensão conhecimentos, conexão fundamental para a demonstração de competências, e para que se atinja as demais dimensões presentes.

\section{Produções e reflexões sobre o itinerário formativo}

As duas intervenções didáticas desenvolvidas foram objeto de pesquisa do ex-bolsista de iniciação à docência, que resultaram em trabalhos publicados em anais de congresso e revistas científicas (Tabela 2). Os trabalhos apresentam resultados que dialogam entre si, e juntos, abordam reflexões sobre os seguintes pontos: i) práticas pedagógicas; ii) ensino de ciências e de biologia; iii) uso de Tecnologias da Comunicação e Informação (TICs); iv) postura discente e docente; v) reflexões sobre o contexto educacional local; vi) processo de formação inicial do professor e vii) desenvolvimento de avaliações sobre os níveis de Letramento Científico (OLIVEIRA-JUNIOR, et al., 2019; OLIVEIRA-JUNIOR; LOPES; MADEIRA, 2019; OLIVEIRA-JUNIOR, no prelo). 
Tabela 2 - Trabalhos desenvolvidos a partir de investigações sobre as intervenções didáticas realizadas.

\section{Trabalhos Desenvolvidos}

Oficina de Roteiros Cinematográficos e as Ciências Biológicas: Implicações de uma Atividade Inovadora no PIBID

Percepções Preliminares Sobre as Interfaces Entre o Letramento Científico e Saberes das Ciências Biológicas

O Recurso Audiovisual como Ferramenta Potencializadora do Letramento Científico: Relatos de Experiências em uma Escola Pública de Salvador, Bahia
Tipo do Trabalho / Local de Submissão

Resumo, publicado no Caderno de Resumos do Congresso de Ensino, Pesquisa e Extensão da UFBA (2019)

Resumo Expandido, publicado nos Anais do XII Seminário Nacional de Formação dos Profissionais da Educação (2019)

Artigo, publicado no Ebook do VIII Encontro Nacional de Ensino de Biologia (2021)

\section{Resultados encontrados}

O trabalho afirma que a construção de roteiros cinematográficos colaborou para a criação de um ambiente de reflexão crítica e contextualizada sobre os conteúdos da Biologia.

O estudo preliminar indicou que os estudantes apresentam especiais dificuldades na compreensão de termos científicos ligados as ciências biológicas, carecendo de uma maior investigação sobre as interfaces entre esse campo do saber e o Letramento Científico.

O recurso audiovisual se apresentou como um artefato capaz de mediar os desafios e tensões entre o Letramento Científico e as Ciências Biológicas, além da promoção de uma mudança de postura do professor frente aos pressupostos teóricos do LC.

Fonte: Elaborado pelos autores (2021).

A formação inicial de professores e professoras "requer uma permanente mobilização dos saberes adquiridos em situações de trabalho, que se constituirão em subsídios para situações de formação, e dessas para novas situações de trabalho" (GATTI, 2014, p. 39). Assim, as vivências teóricas e práticas que permeiam o seu percurso de construção enquanto docente, atuam de maneira formativa. Josso (2020) ressalta as experiências formadoras como fundamentais e enfatiza a necessidade de um trabalho reflexivo sobre as percepções e sentimentos durante o processo de formação.

Ao assumir o desafio da construção de uma prática docente pautada no Letramento Científico, o ex-bolsista enfrentou diversos momentos de "tensionamento". Tal experiência é definida por Lira-da-Silva e Peixoto (2020) como um importante processo que possibilita ao professor em formação momentos de reflexão sobre a sua prática docente.

Primeiramente, houve dificuldades na apropriação dos pressupostos teóricos do Letramento Científico. As diversas definições de LC, assim como o histórico debate do uso da alcunha Literácia Científica versus Alfabetização Científica representou um momento de grande reflexão e estudo sobre os termos. A pesquisa bibliográfica, no entanto, contribuiu diretamente não apenas para o entendimento do conceito, mas para o desenvolvimento de habilidades relacionadas ao processo de pesquisa e sistematização do conhecimento.

Segundo, (re)pensar as questões pedagógicas e metodológicas foi um desafio. As vivências do ex-bolsista enquanto estudante egresso da educação básica pública, deixaram poucas referências de práticas docentes fora do modelo expositivo. Ao se debruçar na construção dos objetivos da sua intervenção didática, foram inúmeros os momentos nos quais o estudante de licenciatura se percebeu produzindo uma intervenção didática pouco integrativa, mecânica e repetitiva.

Outra percepção muito presente durante o desenvolvimento da atividade, foi a quase inexistência de disciplinas curriculares obrigatórias para curso de Licenciatura em Ciências Biológicas da UFBA que rompam o conteudismo e se aproximem de abordagens que 
possibilitem ao professor em formação a interação com questões práticas, humanas e sociais. München (2016) diz que não só as disciplinas escolares, mas as universitárias também apresentam em geral um caráter conteudista, valorizando a apropriação de conceitos sem relacioná-los com a vida prática. Nesse sentido, o ex-bolsista se deparou com uma verdadeira "bolha acadêmica" que hipervaloriza o conteúdo, para construir uma prática que contraria a tudo aquilo que foi vivenciado no seu dia a dia durante a licenciatura.

Desta forma, a abordagem imbricada no LC permitiu ao bolsista uma visão expandida da função social da atividade científica. Santos (2007), já vinha discutindo a importância de se encarar a educação científica como uma prática social, capaz de transformar realidades, diminuir as desigualdades, além de discutir valores práticos e éticos da ciência. Tais valores foram transformadores na ótica e na prática docente, tornando-se presentes em várias outras etapas dentro e fora do referido Programa de Iniciação.

\section{Considerações Finais}

A formação de professores no Brasil é marcada por uma constante superação de desafios institucionais e políticos. A percepção sobre a necessidade da melhoria do sistema educacional sempre foi atravessada por discussões sobre a qualidade na formação dos licenciandos. O surgimento do PIBID representou um grande avanço para a formação inicial de professores, possibilitando um contato direto com a prática docente ainda durante o processo formativo profissional, constituindo-se como espaço de reflexão não só para a prática pedagógica, mas para a educação como um todo. O PIBID de Biologia da UFBA vem se consolidando como um espaço para formação de profissionais da educação, com o incentivo às práticas docentes que rompam modelos tradicionais presentes no Ensino de Ciências e no Ensino de Biologia e que objetivam a criação de espaços onde as discussões sobre ciência e sociedade estejam presentes nas intervenções didáticas construídas.

A adoção do Letramento Científico como pressuposto teórico, resultou em uma narrativa que revelou momentos de reflexão em um dos bolsistas do programa. $\mathrm{O}$ entendimento sobre a necessidade de mudança em sua prática docente foi apresentado através das experiências obtidas durante a construção de intervenções didáticas durante o seu itinerário formativo. Neste caso, a presença de marcos teóricos tais como a Educomunicação, representaram uma preocupação para o uso de referenciais capazes de possibilitar a realização de atividades cujo sentido principal seja uma prática docente preocupada com o desenvolvimento intelectual, crítico e reflexivo.

As experiências narradas e discutidas pelo ex-bolsista demonstraram uma mudança de postura frente a sua prática docente, buscando a incorporação e construção de instrumentos didáticos-pedagógicos que se afastam de modelos ultrapassados de se ensinar e se aprender sobre Ciências. Com base nessas experiências, foi possível analisar as deficiências estudantis na compreensão de termos científicos ligados às Ciências Biológicas e como essas dificuldades comprometeram as possibilidades dos mesmos em embasar os seus argumentos a partir de conceitos científicos. Compreende-se que tais conclusões podem contribuir para outros estudos acerca do perfil docente que se pretende construir nas Licenciaturas e nos Programas de Formação Inicial.

Consideram-se também necessárias investigações sobre a construção dos currículos escolares, em especial a matriz curricular das Ciências da Natureza, diante dos desafios enfrentados por esse campo do saber, ao incorporar os objetivos balizados pelo BNCC e demais pressupostos teóricos do Letramento Científico. Programas como o PIBID exercem, justamente, um papel fundamental ao possibilitar momentos formativos fora das amarras 
curriculares, possibilitando aos seus participantes reflexões permanentes sobre sua prática, permitindo assim uma formação docente ampliada.

\section{Referências}

ALBUQUERQUE, Gabriela; BRAGA, Rodrigo; GOMES, Vinícius. Conhecimento dos alunos sobre microrganismos e seu uso no cotidiano. Revista de Educação, Ciências e Matemática, v. 2, n. 1, 2012.

AUSUBEL, David. The acquisition and retention of knowledge: A cognitive view. Berlin: Springer Science; Business Media, 2012.

BORGES, Maria; AQUINO, Orlando; PUENTES, Roberto. Formação de professores no Brasil: história, políticas e perspectivas. Revista HISTEDBR On-line, v. 11, n. 42, p. 94 112, 2011.

BRANCO, Alessandra et al. O letramento científico na BNCC: possíveis desafios para sua prática. Revista Contemporânea de Educação, v. 15, n. 33, p. 196-215, 2020.

BRASIL, Ministério da Educação. Lei 9.394/96. Lei de Diretrizes e Bases da Educação Nacional. Brasília: MEC, 1996. Disponível em:

http://www.planalto.gov.br/ccivil_03/leis/19394.htm. Acesso em: 15 fev. 2021.

BRASIL. Ministério da Educação. Base nacional comum curricular: educação é a base. Brasília, DF, 2017. Disponível em: http://www.observatoriodoensinomedio.ufpr.br. Acesso em: 10 fev. 2021.

CHENÉ, Adéle. A Narrativa de Formação e a Formação de Formadores. In: NÓVOA, António; FINGER, Matthias (org.). O método (auto)biográfico e a formação. 2. ed. Natal: EDUFRN, 2010, p. 121-132.

DEL PINO, José.; STRACK, Ricardo. O desafio da cientificidade na sala de aula. Revista Pátio Ensino Médio. v. 12, n.01, p. 11-13, 2012.

FLICK, Uwe. Introdução à pesquisa qualitativa. 3. ed. Porto Alegre: Artmed Editora, 2009.

FREITAS, Helena. Formação de professores no Brasil: 10 anos de embate entre projetos de formação. Educação \& Sociedade, v. 23, n. 80, p. 136-167, 2002.

GADOTTI, Moacir. História das Ideias Pedagógicas. 7. ed. São Paulo: Editora Ática, 1999.

GATTI, Bernadete. A formação inicial de professores para a educação básica: as licenciaturas. Revistas PUC. São Paulo, v. 3, n.100, p. 35-46, 2014.

GONÇALVES, Priscila; MACIEL, Moniky; BARROS, José. S. Recursos audiovisuais: uma modalidade didática inovadora no ensino de biologia. Revista de Pesquisa Interdisciplinar. v. 1, n.01, p. $430-436,2017$.

ITOCAZO, Carolina. Tecnologias educacionais nas escolas: fatores envolvidos no processo de adoção, a partir do ponto de vista da educomunicação. Educomunicação e suas áreas de 
Revista de Educação, Ciência e Tecnologia

intervenção: novos paradigmas para o diálogo intercultural. In: SOARES, Ismar; VIANA, Claudemir; XAVIER, Jurema. São Paulo: ABPEducom, 2017.

JAQUES, Marcelo; COPELLI, Giancarlo. A Educomunicação a serviço dos Direitos Humanos. ius gentium, v. 8, n. 5, p. 59-73, 2014.

JOSSO, Marie. Histórias de vida e formação: suas funcionalidades em pesquisa, formação e práticas sociais. Revista Brasileira de Pesquisa (Auto)biográfica, v. 5, n. 13, p. 40-54, 2020.

KRASILCHIK, Myriam; MARANDINO, Martha. Prática de ensino de biologia. 4. Ed. Edusp, 2004.

KRASILCHIK, Myriam. Caminhos do ensino de ciências no Brasil. Em Aberto, v. 11, n. 55, p. 03-08, 2008.

LEITE, Werlayne; RIBEIRO, Carlos. A inclusão das TICs na educação brasileira: problemas e desafios. Revista Internacional de Investigación en Educación, v. 5, n.10, p. 173-187, 2012.

LIRA-DA-SILVA, Rejane. O PIBID-Biologia e os desafios do ensino de Biologia nas escolas públicas de Salvador. In: ASSIS, Alessandra; SANTOS, Ana. (org.). Olhares sobre a docência. Salvador: EDUFBA, 2014.

LIRA-DA-SILVA, Rejane et al. A Produção de vídeos educativos sobre ciências com estudantes de licenciaturas na Universidade Federal da Bahia: os professores comunicam. In: ASSIS, Alessandra et al. (org.). Olhares sobre a Docência: As Contribuições do PIBID UFBA para uma Formação em Rede. Salvador: EDUFBA, 2018.

LIRA-DA-SILVA, Rejane; PEIXOTO, Carine. CTS e a formação inicial de professores de Biologia: O que dizem os egressos? Indagatio Didactica, v. 12, n. 4, p. 207-222, 2020.

LOPES, David; BRAVO, Iara; LIRA-DA-SILVA, Rejâne. Contribuições do Programa Institucional de Bolsa de Iniciação à Docência como iniciativa integradora do ensino e pesquisa: as experiências da oficina "Os enigmas da vida". In: Assis, Alessandra et al. (org). Olhares sobre a Docência: As Contribuições do PIBID UFBA para uma Formação em Rede. Salvador: EDUFBA, 2018.

MADEIRA, Ana Verena; BOMFIM, Gilberto. Subprojeto de Biologia. Salvador, 2020. Disponível em:

https://prograd.ufba.br/sites/prograd.ufba.br/files/subprojeto_pibid_biologia_0.pdf. Acesso em: 15 mar, 2021.

MADEIRA, Ana Verena; BOMFIM, Gilberto. Subprojeto: Biologia. Salvador, 2018. Disponível em:

https://www.moodle.ufba.br/pluginfile.php/583691/mod_resource/content/2/Subprojeto\%20B iologia\%202018\%20FINAL.pdf. Acesso em: 15 mar. 2021.

MAMEDE, Maíra; ZIMMERMANN, Erika. Letramento científico e CTS na formação de professores para o ensino de ciências. Enseñanza de las Ciências, n. Extra, p. 1-4, 2005. 
Revista de Educação, Ciência e Tecnologia

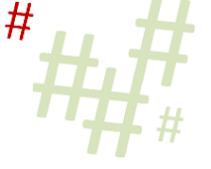

MOREIRA, Benedito. Educomunicação, Ciência e Outros Saberes: um estudo do trabalho colaborativo em narrativas transmídias. Educomunicação e suas áreas de intervenção: novos paradigmas para o diálogo intercultural. In: SOARES, Ismar; VIANA, Claudemir; XAVIER, Jurema. São Paulo: ABPEducom, 2017.

MÜNCHEN, Sinara. The Insertion of The Science-Technology-Society Perspective In The Initial Formation Of Chemistry Teachers. 2016. Tese (Doutorado em Ciências Biológicas) - Universidade Federal de Santa Maria, Santa Maria, 2016.

NÓVOA, António; FINGER, Matthias. O método (auto)biográfico e a formação. 2. ed. Natal: EDUFRN, 2010.

OLIVEIRA-JUNIOR, Nestor; LOPES, David; MADEIRA, Ana Verena. Percepções Preliminares Sobre as Interfaces Entre o Letramento Científico e Saberes das Ciências Biológicas. In: XII Seminário Nacional de Formação de Profissionais da Educação, 12, 2019, Salvador, Bahia. Anais [...]. Salvador: EDUFBA, 2019. p. 1104-1107.

OLIVEIRA JUNIOR, Nestor et al. Oficina de Roteiros Cinematográficos e as Ciências Biológicas: Implicações de uma Atividade Inovadora no PIBID. In: Congresso UFBA de Ensino, Pesquisa e Extensão, 01, 2019, Salvador, Bahia. Anais [...]. Salvador: EDUFBA, 2019, v. 01. p. 856-856.

OLIVEIRA-JUNIOR, Nestor. O Recurso Audiovisual como Ferramenta Potencializadora do Letramento Científico: Relatos de Experiência em uma Escola Pública de Salvador, Bahia. In: OLIVEIRA, Mário; CARDOSO, Nilson; LIMA, Jaqueline. (org). Itinerário de Resistência: Pluralidade e Laicidade no Ensino de Biologia. Campina Grande: Realize Editora. No prelo. E-book.

PINHÃO, Francine.; MARTINS, Isabel. Cidadania e ensino de ciências: questões para o debate. Ensaio Pesquisa em Educação em Ciências (Belo Horizonte), v. 18, n. 3, p. 9-29, 2016.

SANTOS, Wildson. Educação científica na perspectiva de letramento como prática social: funções, princípios e desafios. Revista brasileira de educação, v. 12, n.36, p. 474-492, 2007.

SASSERON, Lucia Helena; CARVALHO, Anna Maria. Alfabetização científica: uma revisão bibliográfica. Investigações em Ensino de Ciências. v. 16, n. 1, p. 59-77, 2011.

SAVIANI, Dermeval. Formação de professores: aspectos históricos do problema no contexto brasileiro. Revista Brasileira de Educação. v.14, n. 40, pp. 143-155, 2009.

SAVIANI, Dermeval. História das ideias pedagógicas no Brasil. 4. Ed. Campinas: Autores Associados, 2013.

SEBASTIÃO, Mariana; BORTOLIERO, Simone; LIRA-DA-SILVA, Rejane Maria. Educação científica e educomunicação: a produção de vídeos científicos com participantes de um centro avançado de ciências em Salvador, Bahia, Brasil. Enseñanza de las ciencias: revista de investigación y experiencias didácticas, n. Extra, p. 3259-3263, 2013.

SILVA, Fabrício. Formação docente no PIBID: temporalidades, trajetórias e constituição identitária. 2017. Tese (Doutorado em Educação) - Programa de Pós-Graduação em Educação, Universidade do Estado da Bahia, Salvador, 2017. 
SOARES, Ismar. Educomunicação: o conceito, o profissional, aplicação: contribuições para a reforma do ensino médio. São Paulo, Paulinas, 2011.

SOUSA, Jennifer Caroline. Documentários Científicos sobre o Mundo Natural no Ensino de Biologia. Ciência \& Educação (Bauru), v. 26, n.01, p. 01-18, 2020.

SOUZA, Igor; RESENDE, Tarcísio. Jogos como Recurso Didático-Pedagógico para o Ensino de Biologia. Scientia cum Industria, v. 4, n.4, p. 181-183, 2017.

SOUZA, Tadeu; STROHSCHOEN, Andreia. O Letramento Científico e Práticas dos Professores de Biologia do Ensino Médio. Centro Universitário UNIVATES, Programa de Pós-Graduação em Ensino de Ciências Exatas, 2016.

Recebido em março de 2021.

Aprovado em maio de 2021. 